\title{
Comment on the paper by Kavitha and Raghukanth, "Regional level forecasting of seismic energy release"
}

\author{
Wen-Nan Wu ${ }^{1}$
}

Received: 26 August 2015/Accepted: 9 December 2015/Published online: 24 December 2015

(C) Akadémiai Kiadó 2015

\begin{abstract}
Kavitha and Raghukanth (Acta Geod Geophys 1-33, 2015) proposed an algorithm to forecast the earthquake energy release for the global seismogenic zones. They concluded that "the developed model is efficient in forecasting the annual earthquake energy release of most of the seismogenic zone". However, for several representative case studies their predictions not only are significantly smaller than the observations but also have unreasonable uncertainty. This commentary discusses some of the problems associated with the earthquake data selection for the input of modeling, which may improve the accuracy of the earthquake energy prediction.
\end{abstract}

Keywords Earthquake forecasting $\cdot$ Seismic hazard assessment $\cdot$ Seismogenic zone

Kavitha and Raghukanth (2015) proposed a time-independent algorithm to forecast the earthquake energy release for the global seismogenic zones on the basis of the global seismicity catalog and the plate boundary model. Such an algorithm seems be useful to determine the most likely moment magnitude and assess the seismic hazard for a specific region. However, for several temporal or spatial cases in their modeling results, the predicted moment energy release is significantly inconsistent with the data. Taking the 2011 $M w 9.0$ Tohoku earthquake as an example, the expected magnitude of the Okhotsk-Pacific region is $M w 8.1$, with a standard deviation of $M w 9.1$. The predicted moment magnitude is significant smaller than the observation, particularly the estimated uncertainty is unreasonably large. The authors ascribed the low accuracy of the prediction to the complexities

This comment refers to the article available at doi:10.1007/s40328-015-0131-7.

Wen-Nan Wu

wennan@earth.sinica.edu.tw; wennan.v.wu@gmail.com

1 Institute of Earth Sciences, Academia Sinica, No, 128, Sec. 2, Academia Road, Nangang Dist., Taipei 11529, Taiwan 
involved in the seismogenic processes and short modeling period, and further proposed to argument earthquake data for improving the accuracy of the prediction. We generally agree with the authors' points. Nevertheless, a reliable dataset is necessary to guarantee the success of training model parameters and obtain a realistic estimate of forecasting. Therefore, for their data selection, we have the following concerns:

(1) Kavitha and Raghukanth defined the intersection between any two tectonic plates as the seismogenic zone, and the minimum width is kept as $120 \mathrm{~km}$ on either side of the plate boundary. All events located within the seismogenic zone were used for analysis. However, most large earthquakes $(M w \geq 8)$ generate along the interface between subducting and overriding plates, and the subduction plate interface earthquakes (mostly located between $20-50 \mathrm{~km}$ depth) have been produced approximately $90 \%$ of the total seismic moment release (Heuret et al. 2011). This is further supported by the data analysis in the paper, that is, $90.7 \%$ of events in the used seismicity catalog are shallower than $70 \mathrm{~km}$. These shallow earthquakes are mainly linked to the subduction plate interface and have more potential to cause seismic hazard. In particular, the deep earthquakes $(>70 \mathrm{~km})$ have different generation mechanisms from these shallow events (Frohlich 2006; Houston 2007). Therefore, it is obviously unreasonable to lump all the events together to predict earthquake energy release for seismic hazard assessment.

(2) $M c$ determines the minimum magnitude of a complete seismicity catalog, and is directly linked to the input data of the artificial neural network (ANN) technique for modeling and forecasting the earthquake energy release. A number of studies have shown that Mc may change with time (Hutton et al. 2010; Michael 2014; Woessner et al. 2006; Woessner and Wiemer 2005). In particular, Michael (2014) shown that the values of $M c$ of ISC-GEM earthquake catalog significantly vary with different time periods. The authors do not take into account the temporal variation in $M c$, which may underestimate the value of $M c$ for the early-period data. This may lead to unreliable trained parameters in the modeling phase, and in turn, obtain questionable forecasting results. Additionally, the authors used the maximum curvature method to determine $M c$, as shown in Fig. 5b, but the maximum curvature of the earthquake magnitude-frequency relation apparently locates at abut $M w 3.2$ rather than $M w 4.5$ by visual examination. Such a determination of $M c$ appears to be questionable.

(3) The seismogenic zones are arranged into the same group based on the correlation of the principle component analysis (PCA), which is used to reduce the unknowns in the forecasting model of the ANN forecasting technique. However, such a grouping may ignore that every seismogenic zone has its own tectonic settings (e.g., plate geometry, plate age, plate converge rate and so on) to relate to the occurrence of earthquakes (e.g., Heuret et al. 2012; Nishikawa and Ide 2014; Song and Simons 2003). Furthermore, recent global studies have shown that a given seismogenic zone may has different seismogenic characteristics along its strike (e.g., Herrendorfer et al. 2015; Nishikawa and Ide 2014; Scholz and Campos 2012). It also seems hardly explain that the spatial distribution of the seismogenic zones for the same seismogenic group is geographically irrelevant. Therefore, we may wonder if it is necessary/appropriate to categorize the 41 seismogenic zones into 16 groups. Most importantly, a relevant question is that whether the underlying assumptions of "future seismic energy release of a particular seismogenic zone in a group is 
considered to be depend on the past seismic energy releases of all other seismogenic zone in that group" is correct.

Acknowledgments This study was financially supported by Ministry of Science and Technology (MOST) of Taiwan, Republic of China, under Grant MOST 104-2811-M-001-053.

\section{References}

Frohlich C (2006) Deep earthquakes. Cambridge University Press, United Kingdom

Herrendorfer R, van Dinther Y, Gerya T, Dalguer LA (2015) Earthquake supercycle in subduction zones controlled by the width of the seismogenic zone. Nat Geosci 8:471-474. doi:10.1038/ngeo2427

Heuret A, Lallemand S, Funiciello F, Piromallo C, Faccenna C (2011) Physical characteristics of subduction interface type seismogenic zones revisited. Geochem Geophys Geosyst 12:Q01004. doi:10.1029/ 2010GC003230

Heuret A, Conrad CP, Funiciello F, Lallemand S, Sandri L (2012) Relation between subduction megathrust earthquakes, trench sediment thickness and upper plate strain. Geophys Res Lett 39:L05340. doi:10. 1029/2011GL050712

Houston H (2007) Deep earthquakes. In: Schubert G (ed) Treatise on geophysics. Elsevier, Amsterdam, pp 321-350. doi:10.1016/B978-044452748-6.00071-7

Hutton K, Woessner J, Hauksson E (2010) Earthquake monitoring in southern California for seventy-seven years (1932-2008). Bull Seism Soc Am 100:423-446. doi:10.1785/0120090130

Kavitha B, Raghukanth STG (2015) Regional level forecasting of seismic energy release. Acta Geod Geophys 1-33. doi:10.1007/s40328-015-0131-7

Michael AJ (2014) How complete is the ISC-GEM global earthquake catalog? Bull Seism Soc Am 104:1829-1837. doi:10.1785/0120130227

Nishikawa T, Ide S (2014) Earthquake size distribution in subduction zones linked to slab buoyancy. Nat Geosci 7:904-908. doi:10.1038/ngeo2279

Scholz CH, Campos J (2012) The seismic coupling of subduction zones revisited. J Geophys Res 117:B05310. doi:10.1029/2011JB009003

Song T-RA, Simons M (2003) Large trench-parallel gravity variations predict seismogenic behavior in subduction zones. Science 301:630-633. doi:10.1126/science.1085557

Woessner J, Wiemer S (2005) Assessing the quality of earthquake catalogues: estimating the magnitude of completeness and its uncertainty. Bull Seism Soc Am 95:684-698. doi:10.1785/0120040007

Woessner J, Schorlemmer D, Wiemer S, Mai PM (2006) Spatial correlation of aftershock locations and onfault main shock properties. J Geophys Res 111:B08301. doi:10.1029/2005JB003961 